\title{
Association between metabolic syndrome and euthyroid nodular goiter: a case-control study
}

\section{Asociación entre el síndrome metabólico y el bocio nodular eutiroideo: un estudio de casos y controles}

\author{
Raisa A. Mayers ${ }^{1,2}$, Andrea Soria Montoya ${ }^{1,3}$, Alejandro Piscoya Rivera ${ }^{1,4}$ Wilmer \\ Gianfranco Silva Caso ${ }^{1,5,6}$ (D) \\ pcmewsil@upc.edu.pe \\ 1 Universidad Peruana de Ciencias Aplicadas, Faculty of Health Sciences, Lima, Peru. \\ 2 Beaumont Hospital, Dearborn, USA, 3 SANNA Clínica El Golf, Lima, Peru. 4 Hospital \\ Guillermo Kaelin de la Fuente, EsSalud - Gastroenterology service, Lima, Peru. 5 Universidad \\ Peruana de Ciencias Aplicadas, Faculty of Health Sciences, Research and Innovation Centre, \\ Lima, Peru. 6 Ministerio de Salud del Perú, Centro de Salud Las Palmas, Tingo Maria, \\ Huánuco, Peru.
}

\section{Abstract}

\section{Background:}

Metabolic syndrome is a cluster of metabolic abnormalities and abdominal obesity; its pathophysiologic basis, insulin resistance, has been shown to act as agent in thyroid cell proliferation. Few studies analyze the relationship between metabolic syndrome and thyroid nodular disease, with a substantial knowledge gap.

Piscoya RA, Silva CWG. Colomb Med (Cali). 2019; 50(4): 239-51. http://doi. org/10.25100/cm.v50i4.2833

Received: 03 Jan 2017

Revised: 03 May 2019

Accepted:30 Nov 2019

Keywords:

Thyroid Nodule, Metabolic Syndrome, Insulin resistance, IGF1 protein, human, Insulin-Like Growth Factor I, IGF2 protein, human, Insulin-Like Growth Factor II, Insulin, Cholesterol, HDL, Obesity, Abdominal, lodine

\section{Palabras clave:}

Nódulo tiroideo, síndrome metabólico, resistencia a la insulina, Proteína IGF1, humana, factor de crecimiento similar a la insulina I, proteína IGF2, humana, factor de crecimiento similar a la insulina II, insulina, colesterol, HDL, obesidad abdominal, yodo.

Copyright: @ 2019. Universidad del Valle.

\section{Objective:}

Determine the association between metabolic syndrome and nodular thyroid disease in a region with adequate iodine intake.

\section{Methods:}

Case-control study. A total of 182 patients referred to radiology to undergo thyroid ultrasonography due to suspicion of thyroid disease. Cases had at least one thyroid nodule greater than $3 \mathrm{~mm}(n=91)$. Controls did not have evidence of thyroid nodules $(n=91)$.

\section{Results:}

Bivariate analysis showed a significant association between metabolic syndrome and the presence of thyroid nodule (OR 2.56, 95\% Cl: 1.41-4.66, $p<0.05$ ). Low levels of HDL (OR 2.81, 95\% Cl: 1.54-5.12, $p<0.05$ ) and impaired fasting glucose (OR 2.05, $95 \% \mathrm{Cl} 1.10$ to $3.78, p<0.05$ ) were significantly associated with the presence of thyroid nodule, independent of the presence of metabolic syndrome. Multivariate analysis maintained the association between metabolic syndrome and thyroid nodule with an OR of $2.96(95 \% \mathrm{Cl} 1.47$ to $5.95, p<0.05)$; similarly, the associations of low levels of HDL (OR 2.77, $95 \% \mathrm{Cl} 1.44$ to $5.3, p<0.05$ ) and impaired fasting glucose (OR 2.23, $95 \% \mathrm{Cl} 1.14$ to $4.34, \mathrm{p}<0.05$ ) with thyroid nodule remained significant.

\section{Conclusion:}

The thyroid nodular disease is associated with increased risk of metabolic syndrome, specifically decreased HDL and impaired fasting glucose levels were the factors that increased association was found. 


\section{Conflicts of interest:}

None

Corresponding autor:

Wilmer Silva-Caso, Universidad Peruana de Ciencias Aplicadas, Av. San Marcos cuadra 2, Chorrillos, Lima, Peru. Phone +51 992154452, e-mail: pcmewsil@upc. edu.pe

\section{Reumen}

\section{Antecedentes:}

El síndrome metabólico es un conjunto de anormalidades metabólicas y obesidad abdominal; Se ha demostrado que su base fisiopatológica, la resistencia a la insulina, actúa como agente en la proliferación de las células tiroideas. Pocos estudios analizan la relación entre el síndrome metabólico y la enfermedad nodular tiroidea, con una brecha de conocimiento sustancial.

\section{Objetivo:}

Determinar la asociación entre el síndrome metabólico y la enfermedad tiroidea nodular en una región con una ingesta adecuada de yodo.

\section{Métodos:}

Estudio de casos y controles. Un total de 182 pacientes remitidos a radiología para someterse a una ecografía tiroidea debido a la sospecha de enfermedad tiroidea. Los casos tenían al menos un nódulo tiroideo mayor de $3 \mathrm{~mm}(\mathrm{n}=91)$. Los controles no tenían evidencia de nódulos tiroideos $(n=91)$.

\section{Resultados:}

El análisis bivariado mostró una asociación significativa entre el síndrome metabólico y la presencia de nódulo tiroideo (OR 2.56, IC 95\%: 1.41-4.66, $p<0.05$ ). Los niveles bajos de HDL (OR 2.81, IC 95\%: 1.54-5.12, $p<0.05$ ) y glucosa en ayunas alterada (OR 2.05, IC 95\% 1.10 a 3.78, $p<0.05$ ) se asociaron significativamente con la presencia de nódulo tiroideo, independiente de la presencia de síndrome metabólico. El análisis multivariado mantuvo la asociación entre el síndrome metabólico y el nódulo tiroideo con un OR de 2.96 (IC 95\% 1.47 a 5.95, p <0.05); de manera similar, las asociaciones de niveles bajos de HDL (OR 2.77, IC 95\% 1.44 a 5.3, p <0.05) y glucosa en ayunas alterada (OR 2.23, IC 95\% 1.14 a 4.34, $p<0.05$ ) con nódulo tiroideo permanecieron significativas.

\section{Conclusión:}

La enfermedad nodular tiroidea se asocia con un mayor riesgo de síndrome metabólico, específicamente la disminución de HDL y los niveles de glucosa en ayunas alterados fueron los factores que aumentaron la asociación.

\section{Remark}

\section{1)Why was this study conducted?}

This study was performed because there is a need for knowledge regarding the relationship between the presence of thyroid nodular disease and metabolic syndrome in patients suffering from these pathologies in our region.

\section{2) What were the most relevant results of the study?}

In the multivariate analysis, the association between the presence of thyroid nodule with the metabolic syndrome OR of 2.96 (95\% CI: 1.47-5.95, p <0.05), also with low HDL levels OR 2.77 (95\% CI: 1.44-), was determined. 5.3, p <0.05) and with the altered basal glycemia OR of 2.23 (95\% CI: $1.14-4.34, \mathrm{p}<0.05$ )

\section{3) What do these results contribute?}

These results provide evidence for the approach and management of patients with nodular thyroid disease and metabolic syndrome as associated diseases. 


\section{Introduction}

Metabolic syndrome is a clustering of metabolic disorders and abdominal obesity associated with an increased risk at developing diabetes, cardiovascular disease, and premature mortality ${ }^{1,2}$. The factors defined are abdominal obesity, high blood pressure, high serum triglycerides, low levels of high density lipoprotein (HDL) and fasting hyperglycemia ${ }^{1,3,4}$. Each of these components is a criterion for diagnosis ${ }^{3,4,5}$. The literature describes a high prevalence worldwide of this syndrome, estimated between 20 and $25 \%$ of the adult population ${ }^{1}$. However, the prevalence depends on the country and diagnostic criteria used for its detection ${ }^{6}$. According to the criteria for metabolic syndrome identification established by the International Diabetes Federation, the prevalence among Peruvian population is $32.8 \%{ }^{7}$.

Metabolic syndrome is strongly associated with insulin resistance. For two decades, studies have reported that insulin resistance might be the central factor for developing this syndrome ${ }^{5,8}$. It is important to remark that the endocrine pancreas increases the production of this hormone due to resistant tissues to insulin action associated with the metabolic syndrome, thus generating a hyperinsulinemic state in the body. Insulin has the ability to act as a factor of the proliferation of thyroid cells, a fact that has been shown in cell culture ${ }^{9}$, which can lead to growth of the thyroid gland and therefore under certain conditions trigger a nodular thyroid disease.

In this context, it is known that receptors for insulin growth factors 1 and 2 (IGF-1, IGF-2) are overexpressed in cell lines thyroid cancer, acting as the main mitogenic and anti-apoptotic factors of cells cancer ${ }^{9,10,11}$.

The information mentioned above states that the development of metabolic syndrome could result in the development of thyroid nodules, which appear in a wide clinical spectrum that includes small asymptomatic nodules, in which the main concern is the exclusion of malignancy, to large nodules with intrathoracic portions causing compressive symptoms ${ }^{12}$.

The prevalence of thyroid nodular disease in the United States is 7\% if it is detected by bimanual palpation of the thyroid gland and is $50 \%$ if detected by ultrasonography ${ }^{12}$.

Because of the difference between the two techniques in early detection of these nodules, ultrasonographic screening of patients with risk factors is important, considering that $5 \%$ of thyroid nodules are detected as malignant carcinomas ${ }^{12}$.

Few studies and none in Peru have analyzed the relationship between metabolic syndrome and nodular thyroid disease and they have revealed an association between these two entities. This is why the objective of our study is determining the association between metabolic syndrome and nodular thyroid disease in a region with adequate iodine intake.

Because the metabolic syndrome can be easily diagnosed by established criteria for its identification, the presence of the association between this syndrome and nodular thyroid disease may lead physicians to suspect of a nodular thyroid disease in patients with metabolic syndrome during the daily medical practice.

\section{Materials and Methods}

Study design and definition of cases and controls

We conducted a cross-sectional, case-control study at "Hospital Nacional Edgardo Rebagliati Martins", which is a national reference hospital that has 1,289 hospital beds and performs an average of 179,881 attentions/year ${ }^{13}$ in Lima, Peru, during 2014. All patients evaluated were residents of areas with adequate levels of iodine (more than $100 \mu \mathrm{g} / \mathrm{L}$ of urinary iodine). All euthyroid patients (defined as TSH values from 0.4 to $4 \mathrm{mLU} / \mathrm{L}$ and free T4 0.9 to $1.8 \mathrm{ng} / \mathrm{dL}$ ) over 18 years, determined by immune chemiluminescent assay with an automatic analyzer, 
who had a thyroid ultrasound showing the presence of a thyroid nodule at least greater than 3 $\mathrm{mm}$, were referred as a case.

Those euthyroid patients over 18 years old, which would have ruled out the presence of thyroid nodule by ultrasonography, were taken as controls. Patients with some condition that would cause the secondary presence of thyroid nodules or erroneous measure to any of the diagnostic criteria of metabolic such as diagnosis of metastatic thyroid cancer syndrome, no history of nodular thyroid disease, previous bariatric surgery, ascites, bedridden patients, pregnant or nursing patients, patients with metabolic syndrome criteria with a difference of three months or more in their registry and lack of at least one of the following data in the medical record: triglycerides, HDL cholesterol and fasting glucose were excluded.

\section{Sample size}

For the calculation of sample size EPIDAT 4.0 was used assuming a confidence level of 95\%, a power of $80 \%$ and a ratio of metabolic syndrome in the population with thyroid nodule of $78.6 \%^{2}$, which would require 91 cases and 91 controls to find an OR of 2.5 or more ${ }^{2}$. Due to the criteria for inclusion and exclusion suggested, 475 patients were evaluated in order to achieve the proposed sample size (Fig. 1).

Outcome measurement

A linear 7.5 MHz transducer was used. To search for the presence of thyroid nodules in both groups of patients, the search was conducted by two experts in the field of diagnostic radiology.

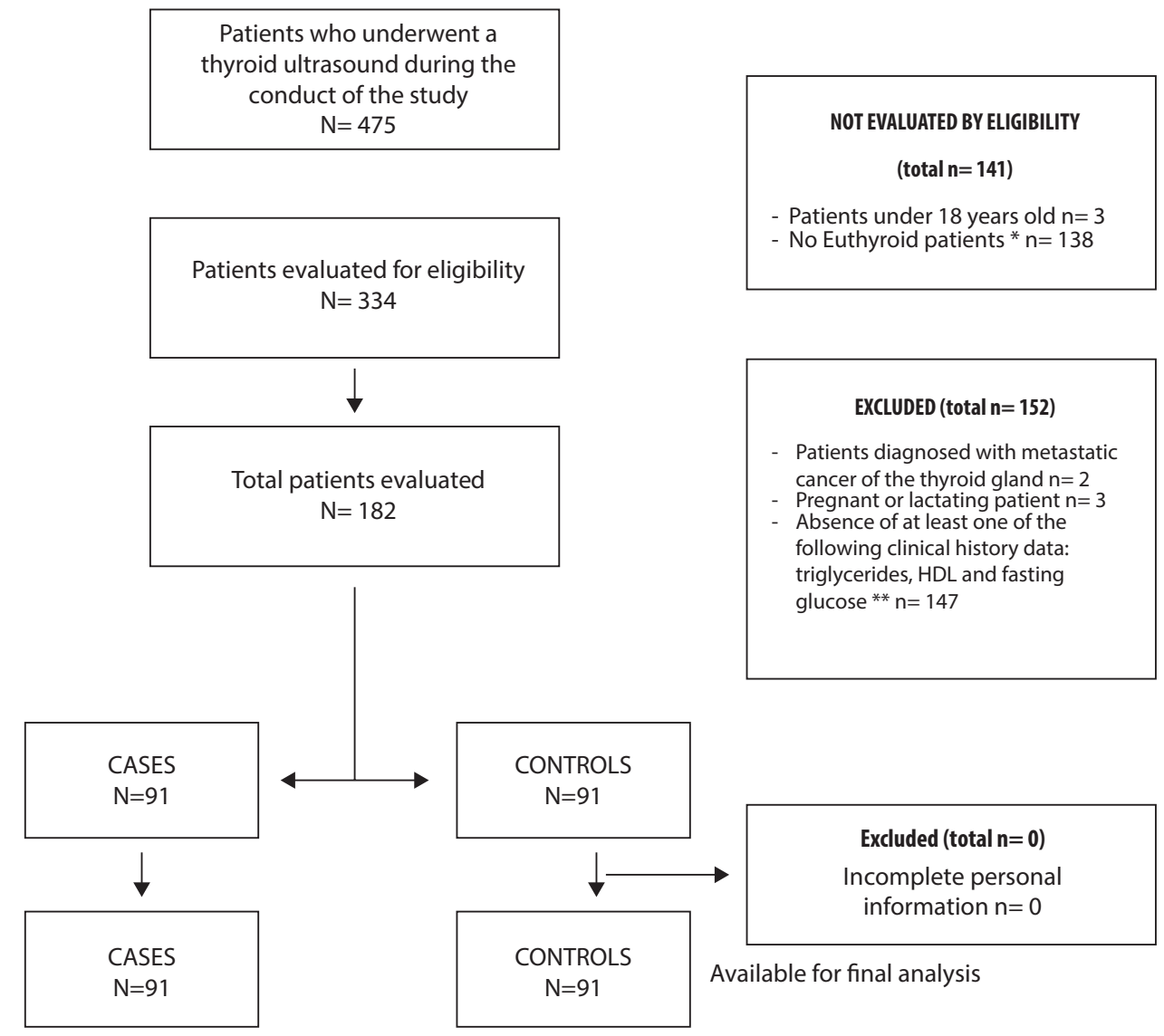

Figure 1. Flow chart of patient selection. ${ }^{*}$ Patients with TSH and free T4 outside the normal ranges proposed (TSH 0.4 to $4 \mathrm{mLU} / \mathrm{L}$ free T4 and 0.9 to $1.8 \mathrm{ng} / \mathrm{dL}$ ). ${ }^{*}$ Patients who did not count with the results of one more of laboratory tests (serum triglycerides, fasting glucose or cholesterol HDL) and/or that they had greater antiquity of three months each other or with other criteria of metabolic yndrome (measured blood pressure and/or measuring the abdominal circumference). 
Table 1. Diagnostic criteria for metabolic syndrome $e^{\star 3}$

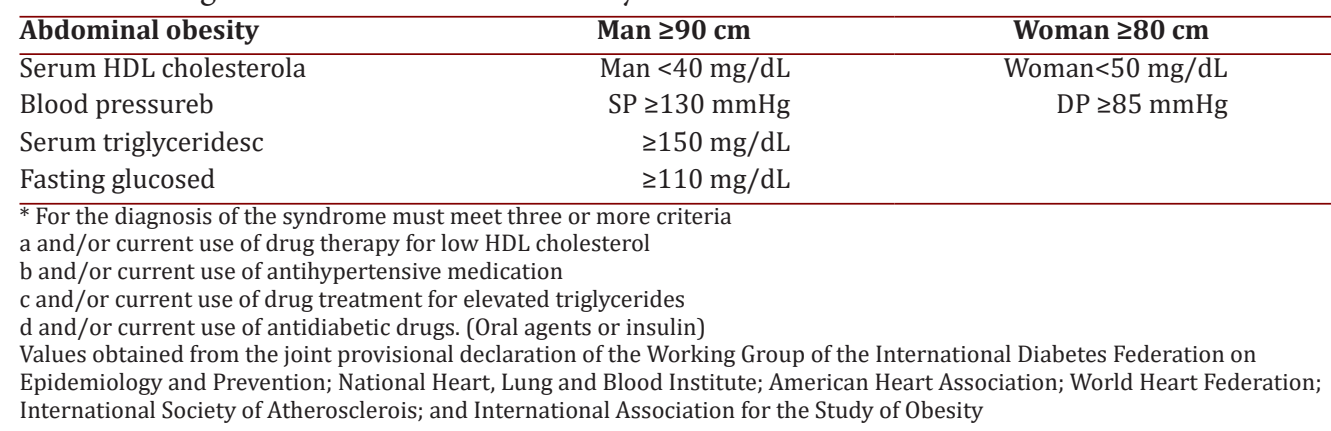

To define the presence of a nodule as such, the study considered all lesions of focal increase of volume or consistency located within the thyroid. They could differentiate from the rest of the parenchyma by a diameter greater than $3 \mathrm{~mm} 14$. TIRADS scale ${ }^{15}$, which groups thyroid nodules in six types (TIRADS I, II, III, IV, V and VI) was used according to their ultrasonographic characteristics.

\section{Definition of variables}

The presence of metabolic syndrome defined by the diagnostic criteria set ${ }^{3}$ (Table 1 ) was determined as association variable. This definition was used because these criteria are the product of a consensus among diverse organizations such as the International Federation of Diabetes, the American Heart Association, International Association for the Study of Obesity, among others; they are used in most studies to show the association proposed in this study and because they consider ethnic variations for abdominal obesity. To obtain these data, the respective measurement taken and the clinical histories of cases and controls revised from which laboratory data as triglycerides, HDL cholesterol and serum glucose obtained.

Values obtained from the joint provisional declaration of the Working Group of the International Diabetes Federation on Epidemiology and Prevention; National Heart, Lung and Blood Institute; American Heart Association; World Heart Federation; International Society of Atherosclerois; and International Association for the Study of Obesity

Such data did not exceed three months of difference compare to the measurement outcome; and clinical data such as the use of antihypertensive and antidiabetic treatment or with lipid lowering agents. In addition, demographics such as gender, age and place of origin were obtained.

\section{Measurement of co-variables}

The blood pressure was measured two times by using a calibrated mercury sphygmomanometer with an interval of at least 2 to $3 \mathrm{~min}$. A mean value was calculated for a final result. The measurement was conducted with the patient sitting (both feet in contact with the ground) and at rest for a minimum of five minutes. Both arms were above heart level and blood pressure in the right arm taken by using a stethoscope. The cuff was inflated extra $30 \mathrm{mmHg}$ as the palpitations stopped and it was deflated at approximately $2 \mathrm{mmHg}$ per second. The value of systolic blood pressure considered the level at which the first Korotkoff sound appeared and the level at which it disappeared; diastolic blood pressure was recorded. The patient did not have drinks with caffeine or smoke or perform exercise for a period of 30 minutes before taking blood pressure. Increased blood pressure was considered if the systolic blood pressure was $\geq 140$ and/or diastolic blood pressure $\geq 90 \mathrm{~mm} \mathrm{Hg}$, or self-reported medical diagnosis and use of antihypertensive medication ${ }^{16,17}$.

Waist circumference was measured as directed by the World Health Organization (WHO), with an inelastic tape measure at the height of the midpoint between the last palpable rib and the iliac crest. The patient was placed in a standing position, with feet together and arms 
loose at the sides. The measurement was taken parallel to the ground, without compressing the abdominal structures and at the end of expiration ${ }^{18}$. The abdominal obesity considered whether waist circumference $\geq 90 \mathrm{~cm}$ was (men) or $\geq 80 \mathrm{~cm}$ (women) ${ }^{1,3}$.

Measurement of laboratory criteria was performed in hospital laboratories, for measuring serum glucose levels the Wiener laboratory commercial kit (Glucose AA liquid enzyme) was used. To measure serum levels of HDL and triglyceride commercial kit from the same laboratory (AA liquid enzymatic cholesterol) was used. The increase in serum triglyceride levels was seen when levels $\geq 150 \mathrm{mg} / \mathrm{dL}$ was found or was currently in drug treatment for elevated triglycerides ${ }^{3}$; low levels of HDL-cholesterol were considered diagnostic criterion when values $<40 \mathrm{mg} / \mathrm{dL}$ were found in men and $<50 \mathrm{mg} / \mathrm{dL}$ in women or there was use of drug therapy for low HDL cholesterol. Finally, the criterion for impaired fasting glucose was considered when glucose was found in fasting $\geq 100 \mathrm{mg} / \mathrm{dL}$ or during current use of antidiabetic drugs (oral agents or insulin).

A standardized methodology was used to measure the height and weight ${ }^{19}$. A stadiometer made out of wood, validated, perpendicular to the ground, split in centimeters, with a sliding header parallel to the ground was used for the measurement of height. The patient was placed with loose arms on the sides and arms and bare feet together and heels in contact with the board and hips, back and head. At the time of measuring, the patient looked at a fixed point, and positioned the head ensuring that the line of sight made an angle of 90 degrees with the body. With the patient in the correct position, the head slid to the patient's hair until it pressed against his head ${ }^{20}$. To record the weight, a calibrated digital scale was used, the patient standing barefoot in the center of the platform, with the weight distributed evenly on both feet, without using any support and loose arms on both sides. The corresponding approximations according to the patient used clothes were performed. ${ }^{20}$.

The Body Mass Index (BMI) was estimated by dividing the person's weight by height squared. According to WHO, a BMI of 18.5 to $24.9 \mathrm{~kg} / \mathrm{m}^{2}$ define normal weight, one of 25 to $29.9 \mathrm{~kg} /$ $\mathrm{m}^{2}$ define overweight and greater than or equal to 30 obesity ${ }^{20}$.

Statistical analysis

A database with information obtained duly codified in Microsoft EXCEL program with double entry and subsequent quality control was developed. Later this database was transferred to STATA 11.2 for statistical analysis.

Means and standard deviations were used for the description of numerical variables (age, height, weight, waist circumference, TSH levels, T4 levels, HDL, triglycerides, systolic and diastolic blood pressure) and for categorical variables, absolute and relative frequencies (gender, BMI and history of diabetes, hypertension, triglycerides and HDL dyslipidemia) were used.

Shapiro Wilk test was used to test the normality of the numeric variables. To compare numerical variables between the two groups, in case of normal distribution, the "Student T" test was used. If it did not have a normal distribution, test Wilcoxon rank sum was used. Chi square test was used for categorical variables to compare population characteristics between cases and controls. Finally, logistic regression was used to calculate odds ratios (OR) and confidence intervals at $95 \%$ adjusting for potential confounders such as age, sex and nutritional status according to body mass index (BMI).

\section{Ethical aspects}

This study has been reviewed and approved by the Ethics Committees of both, the Universidad Peruana de Ciencias Aplicadas (UPC) and the Hospital Nacional Edgardo Rebagliati Martins. Informed consent was applied to all patients who participated in the study before beginning any research activity stating clear information about what would be done and assuring absolute confidentiality. 
Table 2. General characteristics of patients with and without thyroid nodule of a national hospital in Lima

\begin{tabular}{|c|c|c|c|c|}
\hline \multicolumn{3}{|l|}{ Variables } & \multirow{2}{*}{$\begin{array}{c}\begin{array}{c}\text { Patients with } \\
\text { nodules }\end{array} \\
n=91(\%) \\
\end{array}$} & \multirow{2}{*}{$\begin{array}{c}\begin{array}{c}\text { Patients without } \\
\text { nodules }\end{array} \\
\mathrm{n}=91(\%) \\
\end{array}$} \\
\hline \multirow{2}{*}{\multicolumn{5}{|c|}{ Gender }} \\
\hline & & & & \\
\hline Man & 8 & 8.8 & 16 & 17.6 \\
\hline Woman & 83 & 91.2 & 75 & 82.4 \\
\hline \multicolumn{5}{|l|}{ Age } \\
\hline$<40$ & 23 & 25.3 & 28 & 30.8 \\
\hline 40 a 59 & 45 & 49.5 & 38 & 41.8 \\
\hline 60 or mora & 23 & 25.3 & 25 & 27.5 \\
\hline \multicolumn{5}{|l|}{ BMI } \\
\hline Underweight & 33 & 36.3 & 27 & 29.7 \\
\hline Norm weight & 1 & 1.1 & 2 & 2.2 \\
\hline Overweight & 34 & 37.4 & 40 & 44.0 \\
\hline Obese & 23 & 25.3 & 22 & 24.2 \\
\hline \multicolumn{5}{|l|}{ Measurements } \\
\hline $\mathrm{BMI}^{*}\left(\mathrm{~kg} / \mathrm{m}^{2}\right)$ & 26.92 & 4.36 & 26.62 & 4.42 \\
\hline $\operatorname{Size}^{*}(\mathrm{~m})$ & 1.56 & 0.08 & 1.57 & 0.08 \\
\hline Weight $^{* *}(\mathrm{~kg})$ & 64 & 17 & 64 & 15 \\
\hline \multicolumn{5}{|c|}{ Abdominal circumference** $(\mathrm{cm})$} \\
\hline Man & 91.5 & 25.3 & 93.0 & 18.5 \\
\hline Woman & 90.0 & 23.9 & 89 & 12.5 \\
\hline $\mathrm{TSH}^{* *}(\mathrm{mlU} / \mathrm{L})$ & 2.71 & 2.07 & 2.50 & 1.18 \\
\hline $\mathrm{T}_{4} \mathrm{~L}^{* *}(\mathrm{ng} / \mathrm{dL})$ & 1.33 & 0.28 & 1.00 & 0.17 \\
\hline \multicolumn{5}{|l|}{$\mathrm{HDL}^{* *}(\mathrm{mg} / \mathrm{dL})$} \\
\hline Man & 49 & 12.25 & 54 & 8.5 \\
\hline Woman*** & 45 & 12.4 & 52 & 17 \\
\hline Glucose**(mg/dL) & 95 & 35.0 & 90 & 26.4 \\
\hline 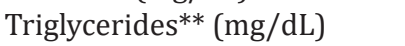 & 121 & 68.0 & 115 & 69.5 \\
\hline Systolic pressure** (mmHg) & 120 & 20 & 115 & 20 \\
\hline Diastolic pressure** (mmHg) & 70 & 10 & 70 & 11 \\
\hline Nodule size ${ }^{* *}(\mathrm{~mm})$ & 12.6 & 11.9 & - & - \\
\hline \multicolumn{5}{|l|}{ Background } \\
\hline Diabetes & 20 & 21.98 & 11 & 12.09 \\
\hline Hypertension & 26 & 28.57 & 22 & 24.17 \\
\hline TG Dyslipidemia & 10 & 10.99 & 15 & 16.48 \\
\hline HDL Dyslipidemia & 9 & 6.59 & 4 & 4.39 \\
\hline
\end{tabular}

*The mean and standard deviation is described.

**The median and interquartile range is described

${ }^{* * *} p=0.035$ Significant difference between the values of HDL in women in the case group compared to the control group

\section{Results}

Population characteristics

The number of potentially eligible participants for the study was 475 . Of these 141 were not considered for eligibility, 3 were under 18 years of age and 138 because they did not have the status of being euthyroid. Of the confirmed eligible $(n=334), 152$ participants were excluded applying the exclusion criteria. The total number of patients evaluated was 182 divided into 91 cases and 91 controls, all of them were included in the study and their results analyzed.

The study included a total number of 182 patients, 91 out of them had at least one thyroid nodule and 91 were the control group (Table 2). The group of patients with thyroid nodule 91.2\% $(n=83)$ were female, while in the control group $82.4 \%$. The median age in the control group was 51 (interquartile range or RI: 27) and in the case group was 50 (RI 21). The most prevalent nutritional status in both groups was overweight, being the $40 \%$ of controls and $34 \%$ of cases, followed by low weight, obesity and normal weight for both groups. In the case group the median size of thyroid nodules was $12.6 \mathrm{~mm}$ (RI: 11.9). 
Table 3. Differences between the metabolic syndrome and its components in patients with and without thyroid nodule

\begin{tabular}{lcccc}
\hline \multirow{2}{*}{ Variables } & \multicolumn{2}{c}{ With nodule } & \multicolumn{2}{c}{ Without nodule } \\
\cline { 2 - 5 } Metabolic syndrome* & \multicolumn{2}{c}{$\mathbf{9 1} \mathbf{( \% )}$} & \\
Yes & 58 & 63.74 & 37 & 40.66 \\
No & 33 & 36.26 & 54 & 59.34 \\
\hline Abdominal obesity & & & & \\
Yes & 70 & 76.92 & 70 & 76.92 \\
No & 21 & 23.08 & 21 & 23.08 \\
\hline Low HDL* & & & & \\
Yes & 58 & 63.74 & 35 & 38.46 \\
No & 33 & 36.26 & 56 & 61.54 \\
High triglycerides & & & 39 & 42.86 \\
Yes & 44 & 48.35 & 52 & 57.14 \\
No & 47 & 51.65 & 40 & 43.96 \\
High blood pressure & & & 51 & 56.04 \\
Yes & 53 & 58.24 & & \\
No & 38 & 41.76 & 26 & 28.57 \\
Impaired fasting glucose & & & & \\
Yes & 41 & 45.05 & 51.43 \\
No & 50 & 54.95 & &
\end{tabular}

Significant difference between the values of HDL in women in the case group compared to the control group $(p<0.05)$. No significant variations for BMI, height, weight, waist circumference, glucose, triglycerides, systolic and diastolic pressure for both groups were found.

Characterization of metabolic syndrome in the population

The presence of metabolic syndrome was associated with $59.3 \%(n=54)$ of patients with thyroid nodule, while in the controls group such entity was found in $36.3 \%(n=33)$ of the patients $(p<0.005)$ (Table 3$)$. It was revealed that the five components of metabolic syndrome are present more often in the group of patients with thyroid nodule being the abdominal obesity (76.9\%) the most frequent component in said group, followed by low HDL level (63.7\%), high blood pressure (58.2\%), high triglyceride level (48.4\%) and basal glucose increased (45.1\%); while the control group found that the most common factor was abdominal obesity (76.9\%) followed by high blood pressure (44.0\%), high triglyceride level (42.9\%), low HDL levels (38.5\%) and altered basal glucose (28.6\%). However, only significant difference was found in the values of low HDL and basal glucose between the two groups.

Table 4. Bivariate and multivariate analysis between metabolic syndrome and thyroid nodule

\begin{tabular}{lrrrr}
\hline \multirow{2}{*}{ Modelo bivariado } & \multicolumn{2}{c}{ Bivariate model } & \multicolumn{2}{c}{ Multivariate model* } \\
\cline { 2 - 5 } Metabolic Syndrome & \multicolumn{2}{c}{ OR (IC 95\%) } & \multicolumn{2}{c}{ OR (IC 95\%) } \\
Yes** & $\begin{array}{r}2.56 \\
\text { No }\end{array}$ & $\begin{array}{r}1.41-4.66 \\
\text { Reference }\end{array}$ & $\begin{array}{r}2.96 \\
1\end{array}$ & $\begin{array}{r}1.47-5.95 \\
\text { Reference }\end{array}$ \\
\hline Individual components & 1 & & & \\
Abdominal & 1 & $0.5-1.99$ & 0.68 & $0.27-1.67$ \\
\hline obesity & & & & \\
Low HDL* & 2.81 & $1.54-5.12$ & 2.77 & $1.44-5.3$ \\
High triglycerides & 1.24 & $0.69-2.23$ & 1.29 & $0.66-2.51$ \\
High blood pressure & 1.77 & $0.98-3.19$ & 2.23 & $0.92-3.38$ \\
Impared fasting glucose** & 2.05 & $1.10-9.78$ & & $1.14-4.34$ \\
\hline Ad
\end{tabular}

${ }^{*}$ Adjusted for age. gender. and nutritional status (BMI)

${ }^{* *} p<0.05$ 
Bivariate and multivariate analysis

In bivariate analysis significant association between the presence of thyroid nodule and metabolic syndrome is evident with an OR of 2.56 (95 CI: \% 1.41-4.66, $p<0.05$ ). Furthermore it was shown specifically that levels of low HDL and impaired fasting glycemia are significantly associated with the presence of thyroid nodule with an OR of 2.81 (95\% CI: 1.54-5.12, $p<0.05$ ) and $2.05(\mathrm{CI} 95 \%: 1.10-3.78, p<0.05)$ respectively.

In multivariate analysis, the association between the presence of thyroid nodule remained with the metabolic syndrome with an OR of 2.96 (95\% CI: 1.47-5.95, $p<0.05$ ), with low HDL levels with OR 2.77 (95\% CI: 1.44-5.3, $p<0.05)$ and the basal glycemia altered with an OR of 2.23 (95\% CI: 1.14-4.34, $p<0.05)$. (Table 4).

Considering the metabolic syndrome as a dichotomous variable, the association with the number of thyroid nodules present in the patient was evaluated. As a result, no association was found to perform the analysis.

\section{Discussion}

This study revealed that the frequency of metabolic syndrome was greater in patients with thyroid nodular disease, about three times more likely than in the absence of this. Furthermore, when analyzing each individual component of the syndrome, independent association was found on two criteria: the presence of low levels of HDL in serum and disturbance basal glycemia. The group of patients with thyroid nodules are almost three times as likely to have low levels of HDL in addition to twice as likely to have impaired glucose levels compared to patients who do not have thyroid nodules.

Currently, there are not many research studies to reveal the proposed association. However, there is a case control study in an area of mild to moderate iodine deficiency, which included 539 patients and took metabolic syndrome as a dependent variable (278 patients in the case group and 261 in the control group) ${ }^{2}$. These results showed that patients suffering of metabolic syndrome had greater percentage thyroid nodules compared to those in the control group ( 50.4 vs $14.6 \%, p<0.0001)$ besides to an increased thyroid volume $(17.5 \pm 5.5$ vs $12.2 \pm 4.2$ $\mathrm{ml}, p<0.0001)$. Also, they proved the association between the formation of thyroid nodules and the presence of insulin resistance obtaining an OR of 3.2 with a confidence interval of $95 \%$ for this association. Another study proving the association proposed in this research ${ }^{21}$, in 2014 was conducted a cohort type study in China including a total of 1061 patients followed up for three years. In its findings the researchers describe the prevalence of thyroid nodule was higher in the group of patients with metabolic syndrome $\left(\mathrm{Ji}^{2}=69.63, p<0.001\right)$, after completion of the analysis of each syndrome component with the presence of thyroid nodules, the result was that abdominal obesity and increased serum triglycerides were associated with the development of thyroid nodules with RR 1.434 and 1.001 respectively, differing with our results in which we found that the associated components are the values of low HDL serum and impaired fasting glucose. A cross-sectional study, with 77 patients older than 65 years with metabolic syndrome showed a poor metabolic control in elderly patients with metabolic syndrome, reflected by high levels of HbAlc, is associated with impaired thyroid morphology and is a risk factor for nodule formation and growth the thyroid in this population. In addition, patients with established type 2 diabetes mellitus identified within this population have larger thyroid volumes than their counterparts who do not suffer from this pathology ${ }^{22}$. These studies, conclude that there is an association between the metabolic syndrome and the presence of thyroid nodules, which reinforces the conclusions of our investigation.

Other studies seek to prove associations between insulin resistance and the appearance of thyroid nodules. Therefore, the importance of these studies is clear considering that this is the pathophysiological basis of the metabolic syndrome; additionally, patients with insulin 
resistance had a higher percentage of nodular thyroid disease and increased thyroid volume compared to patients without the insulin resistance, concluding that at higher levels of circulating insulin, an increased thyroid proliferation develops which translates clinically as thyroid nodules formation; such nodules are larger than those present in patients without resistance to this hormone ${ }^{9}$. A study of case-control with 146 patients (63 cases and 83 controls) to investigate said association, showed that HOMA index taken as a measure for determining insulin resistance was significantly higher in the group of patients with thyroid nodules $(15.87 \%)$ compared to the control group $(10.8 \%)^{11}$.

Another interesting association shown in the literature is the insulin resistance role in the development of thyroid cancer. The outcome revealed that $50 \%$ of patients presented differentiated thyroid cancer insulin resistance, while statistically significant difference of only $10 \%$ in the control group. Furthermore, they claim that in the group of patients with differentiated thyroid cancer, the insulin resistance appeared in $56.3 \%$ of the patients with papillary thyroid cancer and $25 \%$ in follicular thyroid cancer. From these results, we can infer that the insulin resistance besides being a risk factor for the origin of thyroid nodules could be an important indicator of the presence of neoplastic cells in the secondary thyroid nodules to it ${ }^{23}$. When analyzing each component of metabolic syndrome independently with the presence of thyroid nodular disease in this study, it was shown that there is association between decreased serum HDL levels and the occurrence of thyroid nodules. This may be due to the decreased serum HDL levels is one of the components found more prevalent in the population of Peruvian women who suffer from this syndrome, presenting $71.2 \% 7$ to $86.8 \%{ }^{24}$. Furthermore, it has been shown in multiple studies that insulin resistance is associated with reduced HDL levels ${ }^{1,3-5,25}$. Although, a causal relationship of such phenomenon has not been established, it is known that this hormone resistance generates an increase in the catabolism of apolipoprotein A1 26-29, the main component of HDL, which leads to its decline. Another component of the metabolic syndrome associated with the occurrence of thyroid nodules is impaired fasting glucose, which in accordance to some studies is one of the factors with the greatest impact on the appearance of thyroid nodules ${ }^{2}$. It is well known that the presence of the metabolic syndrome determines a hyperinsulinism state in the body where higher circulating levels of insulin cause increased proliferation of thyroid cells. Insulin and thyroid hormones are intimately involved in cell metabolism and thus the excess or deficiency of any of these hormones lead to functional impairment of the other ${ }^{9}$. The physiological and biochemical correlation between insulin levels and the influence of both insulin and iodothyronines on the metabolism of carbohydrates and proteins has been registered. Clinical manifestations include increased thyroid volume and nodule formation accompanied by altered levels of serum glucose ${ }^{9}$.

A study found that fasting plasma glucose was higher in the group with nodular goiter. There were also differences between the groups in terms of HOMA-IR and insulin level. HOMAIR did not correlate with thyroid volume, nodule volume and nodule count ${ }^{30}$. While a prospective study not found difference in thyroid volume or the presence of nodular thyroid diseases among the groups with presence or absence of insulin resistance. However, thyroid volume was significantly associated with the Metabolic Syndrome, these results suggest that the individual components of the Metabolic Syndrome can influence the thyroid nodularity to a certain extent and that together they exert a cumulative effect on the thyroid gland, as described in our results ${ }^{31}$. Another study reports that in participants with presence or absence of thyroid nodules, the thyroid volume correlates significantly with the components of the metabolic syndrome (waist circumference, blood pressure, fasting plasma glucose and serum lipid profiles), in the group Non-nodular thyroid, thyroid volume was also positively related to serum insulin and HOMA-IR levels, unlike the results of other studies ${ }^{32}$.

The associations shown in this study allow us to increase awareness about the risk of developing thyroid nodular disease in patients with metabolic syndrome and promote greater emphasis on controlling and managing components that have been proven greater association to prevent from the appearance of said nodules. There are also studies where it has been 
shown that the use of metformin in patients with small thyroid nodules and insulin resistance, significantly reduce the size thereof ${ }^{33}$.

In our study, we found the following restrictions: ultrasonography, a diagnostic test for the detection of thyroid nodule, despite being the most sensitive it is an operator dependent assuming a measurement bias (for which it was limited to only two operators and used a validated scale); the study population was in a hospital environment and was not chosen randomly, so that the results of this study cannot be extrapolated to the general population.

From this study it can be concluded that the presence of thyroid nodular disease is associated with increased risk of metabolic syndrome, specifically decreased HDL and impaired fasting glucose levels were the factors that increased association was found.

Conducting prospective studies in the future, randomized with greater population are recommended to be able to analyze the relationship between the quantity of thyroid nodes and the metabolic syndrome.

\section{References}

1. International Diabetes Federation. The International Diabetes Federation consensus worldwide definition of the metabolic syndrome. Lisbon: IDF; 2006.

2. Ayturk S, Gursoy A, Kut A, Anil C, Nar A, Tutuncu NB. Metabolic syndrome and its components are associated with increased thyroid volume and nodule prevalence in a mild-to-moderate iodine-deficient area. Eur J Endocrinol. 2009;161(4):599-605. doi: 10.1530/EJE-09-0410.

3. Alberti K, Eckel R, Grundy S, Zimmet P, Cleeman J. Harmonizing the metabolic syndrome: a joint interim statement of the International Diabetes Federation Task Force on Epidemiology and Prevention; National Heart, Lung, and Blood Institute; American Heart Association; World Heart Federation; International Atherosclerosis Society; and International Association for the Study of Obesity. Circulation. 2009;120(16):1640-5. doi: 10.1161/ CIRCULATIONAHA.109.192644.

4. Grundy S, Brewer H, Cleeman J, Smith S, Lenfant C. Definition of metabolic syndrome: report of the National Heart, Lung, and Blood Institute/American Heart Association Conference on Scientific Issues Related to Definition. Circulation. 2004;109(3):433-8. doi: 10.1161/01.ATV.0000111245.75752.C6

5. Grundy S. Metabolic syndrome pandemic. Arterioscler Thromb Vasc Biol. 2008; 28(4):629-36. doi: 10.1161/ ATVBAHA.107

6. Zimmet P, Magliano D, Matsuzawa Y, Alberti G, Shaw J. The metabolic syndrome: A global public health problem and a new definition. J Atheroscler Thromb. 2005;12(6):295-300. doi: 10.5551/jat.12.295

7. Bernabe-Ortiz A, Pastorius-Benziger C, Gilman R, Smeeth L. Sex differences in risk factors for cardiovascular disease: The PERU MIGRANT Study. PLoS One. 2012;7(4):e35127. doi: 10.5551/jat.12.295

8. Haas JT, Biddinger SB. Dissecting the role of insulin resistance in the metabolic syndrome. Curr Opin Lipidol. 2009;20(3):206-10. doi: 10.1097/MOL.0b013e32832b2024.

9. Rezzonico J, Rezzonico M, Pusiol E, Pitoia F, Niepomniszcze H. Introducing the thyroid gland as another victim of the insulin resistance syndrome. Thyroid. 2008;18(4):461-4. doi: 10.1089/thy.2007.0223

10. Frittitta L, Sciacca L, Catalfamo R, Ippolito A, Gangemi P, Pezzino V, et al. Functional insulin receptors are overexpressed in thyroid tumors: is this an early event in thyroid tumorigenesis? Cancer. 1999;85(2):492-8. doi: 10.1002/(sici)1097-0142(19990115)85:2<492::aid-cncr30>3.0.co;2-i

11. Yasar HY, Ertugrul O, Ertugrul B, Ertugrul D, Sahin M. Insulin resistance in nodular thyroid disease. Endocr Res. 2011;36(4):167-74. doi: 10.3109/07435800.2011.593011. 
Association between metabolic syndrome and euthyroid nodular goiter: a case-control study

12. Hegedüs L. The thyroid nodule. N Engl J Med. 2004; 351(17):1764-71. doi: 10.1056/NEJMcp031436

13. EsSalud. Sistema Estadístico de Salud (SES). Lima: EsSalud; 2015.

14. Rivera-Moscoso R, Hernández-Jiménez S, Ochoa-Sosa A, Rodríguez-Carramza S, Torres-Ambriz P. Diagnóstico y tratamiento del nódulo tiroideo: posición de la Sociedad Mexicana de Nutrición y Endocrinología. Rev Endocrinol Nutrición. 2010;18(1):34-50.

15. Moifo B, Oben TE, Tambe J, Blanc F, Gonsu FJ. Reliability of thyroid imaging reporting and data system (TIRADS) classification in differentiating benign from malignant thyroid nodules. OJRad. 2013;3:103-7. doi: 10.4236/ojrad.2013.33016

16. James PA, Oparil S, Carter BL, Cushman WC, Dennison-Himmelfarb C, Handler J, et al. 2014 evidencebased guideline for the management of high blood pressure in adults: report from the panel members appointed to the Eighth Joint National Committee (JNC 8). JAMA. 2014;311(5):507-20. doi: 10.1001/jama.2013.284427

17. Mancia G, Fagard R, Narkiewicz K, Redon J, Zanchetti A, Böhm M, et al. 2013 ESH/ESC guidelines for the management of arterial hypertension: the Task Force for the Management of Arterial Hypertension of the European Society of Hypertension (ESH) and of the European Society of Cardiology (ESC). Eur Heart J. 2013;34(28):2159-219. doi: 10.1001/jama.2013.284427

18. World Health Organization. Waist circumference and waist-hip ratio: report of a WHO expert consultation. Geneva: WHO; 2011

19. Lohman T, Roche A, Martorell R. Anthropometric standardization reference manual. Champagne, Illinois, Human Kinetic Books, 1988.

20. Bastemir M, Akin F, Alkis E, Kaptanoglu B. Obesity is associated with increased serum TSH level, independent of thyroid function. Swiss Med Wkly. 2007;137(29-30):431-4. doi: 2007/29/smw-11774

21. Yin J, Wang C, Shao Q, Qu D, Song Z, Shan P, et al. Relationship between the Prevalence of thyroid nodules and metabolic syndrome in the iodine-adequate area of Hangzhou, China: a cross-sectional and cohort study. Int J Endocrinol. 2014;2014:675796. doi: 10.1155/2014/675796.

22. Blanc E, Ponce C, Brodschi D, Nepote A, Barreto A, Schnitman M, et al. Association between worse metabolic control and increased thyroid volume and nodular disease in elderly adults with metabolic syndrome. Metab Syndr Relat Disord. 2015;13(5):221-6. doi: 10.1089/met.2014.0158

23. Rezzónico JN, Rezzónico M, Pusiol E, Niepomniszcze H. Increased prevalence of insulin resistance in patients with differentiated thyroid carcinoma. Metab Syndr Relat Disord. 2009;7(4):375-80. doi: 10.1089/ met.2008.0062

24. Pajuelo J, Sánchez J. El síndrome metabólico en adultos, en el Perú. An Fac Med (Lima). 2007; 68(1):3846. doi: $10.15381 /$ anales.v68i1.1237

25. Mottillo S, Filion KB, Genest J, Joseph L, Pilote L, Poirier P, et al. The metabolic syndrome and cardiovascular risk a systematic review and meta-analysis. J Am Coll Cardiol. 2010;56(14):1113-32. doi: 10.1016/j.jacc.2010.05.034

26. Robins SJ, Rubins HB, Faas FH, Schaefer EJ, Elam MB, Anderson JW, et al. Insulin resistance and cardiovascular events with low HDL cholesterol: the Veterans Affairs HDL Intervention Trial (VA-HIT). Diabetes Care. 2003;26(5):1513-7. doi: 10.2337/diacare.26.5.1513

27. Laws A, Reaven GM. Evidence for an independent relationship between insulin resistance and fasting plasma HDL-cholesterol, triglyceride and insulin concentrations. J Intern Med. 1992;231(1):25-30. doi: 10.1111/ j.1365-2796.1992.tb00494.x 
Association between metabolic syndrome and euthyroid nodular goiter: a case-control study

28. Golay A, Zech L, Shi MZ, Jeng CY, Chiou YA, Reaven GM, et al. Role of insulin in regulation of high density lipoprotein metabolism. J Lipid Res. 1987;28(1):10-8.

29. Stalder M, Suenram P, Suenram A. Relationship Between plasma insulin levels and high-density lipoprotein colesterol levels in healthy men. Diabetologia. 1981;21(6):544-8. doi: 10.1007/bf00281546

30. Aydogan Y, Altay M, Ünsal O, Kaplanoglu V, Çagir Y, Yildiz C, et al. An assessment of the relationship between thyroid nodule characteristics, insulin resistance and arterial stiffness in euthyroid nodular goiter. Endocrine. 2018;62(2):440-447. doi: 10.1007/s12020-018-1701-6

31. Kir S, Aydin Y, Coskun H. Relationship between metabolic syndrome and nodular thyroid diseases. Scand J Clin Lab Invest. 2018;78(1-2):6-10. doi: 10.1080/00365513.2017.1402363

32. Dauksiene D, Petkeviciene J, Klumbiene J, Verkauskiene R, Vainikonyte-Kristapone J, Seibokaite A, et al. Factors associated with the prevalence of thyroid nodules and goiter in middle-aged euthyroid subjects. Int $\mathrm{J}$ Endocrinol. 2017; 2017:8401518. doi: 10.1155/2017/8401518.

33. Rezzónico J, Rezzónico M, Pusiol E, Pitoia F, Niepomniszcze H. Metformin treatment for small benign thyroid nodules in patients with insulin resistance. Metab Syndr Relat Disord. 2011;9(1):69-75. doi: 10.1089/ met.2010.0026. 